\title{
Proceeding
}

Supplementary Issue: Summer Conferences of Sports Science. Costa Blanca Sports Science Events, 20-21 September 2019. Alicante, Spain.

\section{School and sport: The high-level student-athletes in Italy}

FRANCESCA D'ELIA

University of Salerno, Italy

\begin{abstract}
The Italian Ministry of Education since 2015 launched a trial "School and sport" addressed to high-level student-athletes that attend high school. The aim of this trial is to contrast not only the dropping out of the school but also one of the sports of the high-level student-athletes. The project proposes training activities aimed at teachers who teach students-athletes and that take into account the psychological aspects that these students face on daily. From the available data, the project had a good feedback in terms of participation and diffusion. The present study is aimed to search a hypothesis to give a solution how it is possible to combine study and high-level performance, in addition to study in deep the high-level studentathletes status and diffusion. The project should significantly reduce the criticalities in the school education of these students by supporting schools in planning effective actions that promote the right to study and educational success of students who practice high-level competitive sport. Keywords: Sport; School dropout; School organization.
\end{abstract}

\section{Cite this article as:}

D'Elia, F. (2019). School and sport: The high-level student-athletes in Italy. Journal of Human Sport and Exercise, 14(5proc), S2031-S2036. doi:https://doi.org/10.14198/jhse.2019.14.Proc5.25

Corresponding author. University of Salerno, Italy.

E-mail: fdelia@unisa.it

Supplementary Issue: Summer Conferences of Sports Science. Costa Blanca Sports Science Events, 20-21 September 2019. Alicante, Spain.

JOURNAL OF HUMAN SPORT \& EXERCISE ISSN 1988-5202

(C) Faculty of Education. University of Alicante

doi:10.14198/jhse.2019.14.Proc5.25 


\section{INTRODUCTION}

The official presence of sport activity in the Italian school curricula dates back to the 1950s, when it was established that in parallel with the implementation of the programs in effect at the time for the teaching of physical education, sports activities were also practiced. Over time the competitive activity has found favourable acceptance and has been consolidated thanks to the promotion of school sports through initiatives such as the Youth Games (Cirillo, et al., 216), nowadays become Student Championships, which intend to direct young people to practice sport. More generally, the initiatives promoted by Italian Ministry of Education, through the implementation of specific projects in schools, are aimed at promoting healthy lifestyles and enhancing diversity through sport (D'Isanto, 2016, Gaetano, 2012). Thus, sport activity becomes a unique means to prevent phenomena of obesity, violence, bullying, racial and gender discrimination. Practicing sport activities supports, on the one hand, the development of personal skills, improves self-esteem and autonomy and teaches how to manage anxiety and stress (Raiola, 2019, 2017, 2015ab, 2013); on the other hand, it also stimulates relational capacity, adaptation to the environment and social integration. Specifically, the initiatives promote by the Italian Ministry of Education (MIUR, 2009ab) are aimed at disseminating a correct culture of sport, contrasting early school drop-out, facilitating the inclusion of the weakest segments of the school population, and favouring the active participation of students with disabilities. Sport appears, within this educational path, as a natural expansion of knowledges also in the perspective of social inclusion.

Every year the Italian Ministry of Education promotes the fulfilment of sports activities in accordance with Italian National Olympic Committee (CONI), the Sports Federations and Sports promotional body and it is also involved in the implementation of National plans for the implementation of interventions aimed at strengthening physical and sports activities in the Italian high schools. The Italian Ministry of Education promotes and supports the important function that sport activity plays in the whole educational program of the Italian school to meet the needs of families, in order to contribute to the development of the student's personality, to his autonomous adaptation to the environment, to a correct health education and to awareness and related behaviours that allow to manage one's own well-being and one's physical and mental health.

The importance of sport activity in the school environment also emerges from the recent "Reform of the national education and training system and mandate for the reorganization of the current legislative regulations" Law 13 July 2015, n. 107 which, in art. 1, paragraph 7, among the priority educational objectives, identifies the strengthening of physical education and sport and the development of behaviours inspired by a healthy lifestyle, with particular reference to nutrition, physical education and sport, and attention to the protection of the right to the study of students practicing competitive sports. To respond to the need to protect the right to study of these students in order to combine a school career with a sporting one, also with the aim to oppose the phenomenon of early school leaving, with Ministerial Decree n. 935 of December 11st, 2015, pilot project was started, pursuant to and in accordance with article 11 of the Decree of the President of Republic (D.P.R.) n. 275 of 8 March 1999, and it held in the school years 2015/2016, 2016/2017 and $2017 / 2018$ with the aim of identifying actions addressed at providing educational supports to schools that have high level student-athletes.

The available data from Italian Ministry of Education show that the pilot project had a good feedback in terms of participation and diffusion, therefore, with Ministerial Decree nr. 279 of April 4th, 2018, the high level student-athletes project was extended for five school years (from 2018/2019 to 2022/2023) providing for an innovative type of training, also supported by digital technologies, for high-level student-athletes enrolled in state and private Italian high schools and identified on the basis of the criteria established in agreement with the CONI and the Italian Paralympic Committee. Therefore, the present study is aimed, in addition to study 
in deep the high-level student-athletes status and diffusion, also to verify how it is possible to combine study and high-level performance.

\section{THE HIGH-LEVEL STUDENT-ATHLETES PROJECT}

The aim of the project is to overcome the criticalities that may occur during the educational path of studentathletes, with particular reference to the difficulties they encounter to attend regularly lectures, as well as the time they are able to dedicate to individual study. The adoption of a teaching/learning methodology based on digital technologies, together with specific and complementary educational and organizational choices, can constitute valid supports for the personalization of the training path of the student-athletes, in order to achieve educational goals.

The project establishes the identification of one or more referent teachers for each school institute adhering to the initiative, which have the task to coordinate the relationship with the interested sports clubs and to define, with the competent class councils, the Personalized Formative Path for each student-athlete. Within this formative path, up to $25 \%$ of personalized number of hours the student-athletes can be used online, either through the use of a specific e-learning platform prepared at national level, or through videoconferences, Skype sessions, web conference, or other tools identified by the school institutions. All the activities related to the project must be certified by the class council, also for the purpose of admission to the next school year, or to the final state exam of the high school.

The project considers a single method of participation, through the approval of the Personalized Education Planning (PFP) by the class council that will also identify one or more school tutor (generally a PE teachers) and an external project referent (sports tutor) indicated by the relative sports organization, by the Sports Federation or by the Associated Sports Disciplines or reference professional league.

In order to support students-athletes in combining workouts, the activities of preparation and participation in competitions with their educational path and the time to commit to individual study, it seems useful to pay the attention of the class councils, even within the scope of their teaching and planning autonomy, on the opportunity to insert specific indications in the PFP on the scheduling and methods of tests and assessment of learning outcomes.

There is the opportunity to take advantage of a special digital platform as an integrative tool to support teaching, with shared methods and materials for the benefit of the schools belonging to the project network. These materials can be effectively used for the personalization of training path, particularly in cases of prolonged absences of the student-athlete.

\section{WHO AND HOW MUCH ARE THE STUDENT-ATHLETES?}

All high schools attended by high-level student-athletes identified on the basis of possession of the minimum necessary requirements participate in the experimental training project. These requirements (below) are proposed by the involved sport institutions (CONI, Italian Paralympic Committee and related Sport Federations and sports association affiliated to them and / or recognized). The number of schools and of students participant to the project in the 2018/2019 school year has almost increased compared to the previous year: from 1505 students adherent in the school year 2017-18 there were about 7600 applications (1275 schools involved) for participation in the school year 2018-19 and are arranged as follow:

1. 449 students' representatives of the absolute National and / or of the relative youth categories; 
2. 21 students' athletes involved in the preparation of the Olympic and Paralympic Games (summer and winter) and youth;

3. 1099 students recognized as "Athlete of National Interest" of the National Sports Federation or of the Associated Sports Disciplines of reference;

4. 2434 students for individual sports, athletes in the top 36 of the national ranking;

5. For professional team sports activities, recognized pursuant to law n. 91/1981, 2953 student athletes participating in the following national championships:

- Soccer A, B and C leagues; Primavera and Berretti A, B and C leagues; under 17, under 16 and under $15 \mathrm{~A}, \mathrm{~B}$ and $\mathrm{C}$ leagues;

- Basketball A1, A2, B leagues; Under 20, Under 18, Under 16 and Under 15 Excellence.

6. For non-professional team sports, 596 student-athletes participating in the National Championships of $A, A 1, A 2$ and $B$ leagues including the Championships of Excellence. For volleyball athletes participating in the $A 1, A 2$ and B men's championships and A1, A2, B1 and B2 female's championships.

The most practiced sports are football, basketball and swimming.

\section{THE PERSONALIZED FORMATIVE PROJECT}

The aim of the student-athletes project is to improve action and to support schools in planning effective actions that allow them to concretely promote the right to study and the educational success of students that compete in high-level sports. The afore mentioned Ministerial Decree (279/2018) has integrated and implemented the provisions of art. 4 of the D.P.R. 275/99: "in the exercise of didactic autonomy the educational institutions regulate the timing of the teaching and the development of the learning and activities in the most suitable way for the type of studies and the learning rhythms of the students. To this end, educational institutions can adopt all the forms of flexibility they consider appropriate". Flexibility finds its fulfilment in the Personalized Formative Project which provides adaptations to teaching / learning, tests and assessment activities. In particular, firs of all are specified the data relating to the student (personal data, period of implementation of the intervention, class coordinator, teacher and Special Educational Needs area contact person), then they are established the general educational objectives that are to be achieved with the PFP, the general organization of the educational path, the measures adopted for the work-related learning path and the specific organization for each learning subject. For each learning, the following are indicated: the personalized methodological / didactic measures adopted (for example: distance learning activities provided by the Institute and / or on ministerial platforms, use of lecture notes and support teaching materials, recovery activities, tutoring, etc. ); the organization and the custom methods of checks (for example: scheduling of written and oral tests, oral tests to compensate written tests, dispensation from overlapping tests on several learning subjects in the same day, dispensation from the tests following the return from important competitive commitments, etc.).

\section{DISCUSSION AND CONCLUSIONS}

National strategies implemented in Italy to promote and to defend sport at school show the awareness of a phenomenon that involve many aspects of our lives and that has a great potential for educational purposes. Sport is an instrument to prevent, to support and to develop during school age, so the sport practice should be encouraged at all levels from beginner to competitor, but we also need to get ready the schools and the students both for practicing sport and for achieving learning outcomes. In response to the need for combining study and sport activities, in particular at high level, the "high level student-athletes project" represents a way 
to significantly reduce the criticalities in the school education of student-athletes by supporting schools in planning effective actions that promote the right to study and the educational success of students who practice high-level competitive sport. The actions proposed are dispensative and / or compensatory and they are mainly related to the scheduling of written and oral tests and the start-up of teaching/learning methods based on e-learning and online activities, all this to allow the students to nurture their passions and aptitudes with nothing left to ask for. For this purpose, the $25 \%$ of the total number of hours provided in alternative and complementary modalities, personalized for the student-athlete that can be used online, both through the use of a specific e-learning platform prepared at national level, and through videoconferences, skype sessions, web conferences, or other tools identified by the institutes, could be extended to the curricular hours of the local school institution pursuant to the art 8 of DPR 275/99 till the maximum hours expected. These activities, additional to the $25 \%$ of total number of hours, must be coherent with the learning outcomes set for the class where the student athlete is inserted and should focus on performance-related disciplines such as new technologies, the biological implications of performance, the social economic value of competitive sport. In this way we would adopt the teaching methods related to e-sports and e-games (Viscione et al., 2019a), the methodology of teaching games for understanding TgfU and the involvement of the teacher athlete in the system (Viscione et al., 2019b). This new articulation of the teaching/learning organization and the school management would also benefit the entire school system with a projection towards a school more calibrated towards the acceptance of the sports performance as a shared element.

\section{REFERENCES}

Cirillo, G., Nughes, E., Acanfora, A., Altavilla, G., D'Isanto, T. (2016). Physical and sport education testing by quantitative and qualitative tools in assessment in senior school: A proposal, Sport Science, 9, pp. 97-101.

D'isanto, T. (2016). Pedagogical value of the body and physical activity in childhood Sport Science, 9, pp. 13-18.

Gaetano, R. (2012). Motor learning and didactics into physical education and sport documents in middle school-first cycle of education in Italy, Journal of Physical Education and Sport, 12 (2), pp. 157-163.

Raiola, G., (2019). Complex study for an epistemology of Exercise and sport sciences: a) key concepts of both ERC subpanels and CUN keywords; b) Physical training and sport methodology sciences academic disciplines in pedagogy recruitment sector and biomedical one: a correlationships study Journal of Physical Education and Sport vol.19(Supplement issue 5), pp. 1748 - 1754.

Raiola, G. (2017). Motor learning and teaching method, Journal of Physical Education and Sport, 17, art. no. 236, pp. 2239-2243.

Raiola, G.(2015a). Sport skills and mental health, Journal of Human Sport and Exercise, 10 (Specialissue), pp.S369-S376. http://dx.doi.org/10.14198/ihse.2015.10.Proc1.27

Raiola, G. (2015b). Inclusion in sport dance and self perception Sport Science, 8, pp. 99-102.

Raiola, G. (2013). Body knowledge and motor skills, Knowledge Cultures, 1 (6), pp. 64-72.

Viscione I., D'Elia F. (2019). Augmented reality for learning in distance education: the case of e-sports, Journal of Physical Education and Sport Vol.19 (Supplement issue 5), 2047 - 2050.

Viscione I., Romano E. (2019). Elements and methods of organization, design and management of extracurricular sports activities. Journal of Physical Education and Sport, Vol.19 (Supplement issue 5), $1767-1772$.

DPR 8 march 1999, n. 275 "Regulation containing rules on school's autonomy pursuant to art. 21 Law 15 March 1997, n. 59".

Law 13 July 2015, n. 107 "Reform of the national education and training system and mandate for the reorganization of the current legislative regulations". 
Ministerial Decree 10 April 2018 n. 279 "High level student-athletes project - school years 2018/20192022/2023".

Ministerial Decree 11 December 2015 n. 935 "Teaching pilot project for high level student-athletes".

MIUR - Italian Ministry of Education (2009a). Linee guida per le attività di educazione fisica, motoria e sportiva nelle scuole di primo e secondo grado. - Indirizzi operativi. Miur - 16 ottobre 2009, prot. 5163.

MIUR - Italian Ministry of Education (2009b). Linee guida sulla riorganizzazione delle attività di educazione fisica e sportiva nelle scuole secondarie di I e II grado. Miur - 4 agosto 2009, prot. 4273.

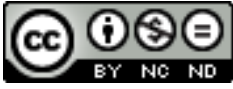

This work is licensed under a Attribution-NonCommercial-NoDerivatives 4.0 International (CC BY-NC-ND 4.0). 